\title{
The action of CGRP and SP on cultured skin fibroblasts
}

Review Article

Bernardo Hochman ${ }^{1 *}$, Vanina M Tucci-Viegas ${ }^{1,2}$, Paola KP Monteiro ${ }^{1}$, Jerônimo P França ${ }^{3}$, Silvana Gaiba ${ }^{1,3}$, Lydia M Ferreira ${ }^{1}$

${ }^{1}$ Plastic Surgery Division, Department of Surgery,

Postgraduate Program in Translational Surgery,

Universidade Federal de São Paulo (Unifesp),

04024-002 - São Paulo/SP, Brazil

${ }^{2}$ Department of Agricultural and Environmental Sciences,

Universidade Estadual de Santa Cruz (UESC),

45662-900 - Ilhéus/BA, Brazil

${ }^{3}$ Department of Biological Sciences,

Universidade Estadual de Santa Cruz (UESC),

45662-900 - Ilhéus/BA, Brazil

Received 12 October 2013; Accepted 22 December 2013

Abstract: Background/purpose: Calcitonin gene-related peptide (CGRP) is the most abundant neuropeptide in the skin, followed by substance $P(S P)$, vasoactive intestinal peptide (VIP), and other neuropeptides in smaller amounts. The proliferative effect of neuropeptides on fibroblasts may affect wound healing and may be associated with hyperproliferative skin and mesenchymal disorders. Understanding the neuropeptidergic action on fibroblasts may provide relevant information to a deeper comprehension of the healing process. This study reviews the action of the main neuropeptides, CGRP and SP, on cultured human skin fibroblasts. Methods: A systematic literature search was conducted on Medline and Web of Science databases on December 21, 2013. Results: A total of 74 articles were retrieved using the proposed search strategies and 3 were found in the references section of the selected articles. Thirteen of the retrieved articles studied the action of CGRP and SP on cultured human skin fibroblasts, 12 of which related to SP and 1 related to both CGRP and SP. Conclusion: Only one study was retrieved about the action of both CGRP and SP on cultured human skin fibroblasts. Further studies are necessary to investigate CGRP on skin fibroblasts and its role in the fibroplasia phase of wound healing.

Keywords: Calcitonin gene-related peptide $\bullet$ Substance $P \bullet$ Fibroblasts $\bullet$ Wound healing $\bullet$ Skin

(C) Versita Sp. z 0.0 .

\section{Key points:}

- Neurogenic inflammation promotes the release of cytokines and growth factors, inducing extracellular matrix synthesis by fibroblasts in the healing phase. Neurogenic inflammation has a direct modulator effect on the subsequent phases of the healing process, especially on the proliferative phase.

- Neuropeptides, especially CGRP and SP, probably have a specific and active participation in the process of fibrosis, and directly act in the proliferative phase of wound healing.

- CGRP is the most abundant neuropeptide in the skin, followed by SP, VIP, and other neuropeptides in smaller amounts.

- The aim of this study was to review the action of the main neuropeptides, CGRP and SP, on cultured human skin fibroblasts.
- VIP and CGRP, alone or in combination with SP, stimulate the proliferation of murine and human keratinocytes; however, the functional role of VIP and CGRP in skin fibroblasts is not well defined.

- $\mathrm{SP}$ is one of the most potent vasodilators; it releases nitric oxide from endothelial cells. This effect is 100 times more potent than that of histamine at similar concentrations. SP produces erythema and edema in a dose-dependent manner, but unlike CGRP, it induces plasma extravasation.

- Unlike CGRP, SP induces human mast cell degranulation with release of histamine.

- SP also induces proliferation of human dermal fibroblasts and human and murine keratinocytes and stimulates neovascularization in vivo and proliferation of endothelial and smooth muscle cells.

- $\quad \mathrm{SP}$ and CGRP are frequently present in the same nerve fiber. SP release may induce the co-release 
of CGRP, which in turn may enhance the action of $\mathrm{SP}$, although CGRP may have long-lasting effects. The release of SP or CGRP may induce an increase in the levels of SP receptors.

- The fact that human skin fibroblasts express neuropeptides receptors suggests that they may respond to SP and other neuropeptides. For instance, exogenous SP was shown to induce autocrine production of SP by human skin fibroblasts.

- Human skin fibroblasts express mRNA for RAMP1, indicating that these cells have low-expression of (but still express) CGRP receptors.

- The ability of SP to induce synthesis and proliferation of human dermal fibroblasts and keratinocytes is well known. SP was shown to increase human fibroblasts proliferation in a concentration-dependent manner. The addition of SP to cultured human dermal fibroblasts also increased the motility of fibroblasts in a concentration-dependent manner.

- SP exerts chemoattractant effects on human skin fibroblasts, triggering a concentration-dependent migratory response, and $\mathrm{NK}-1 \mathrm{R}$ was shown to be responsible for this effect. The ability of SP to promote chemotaxis in human fibroblasts is another proinflammatory activity of this neuropeptide, extending to the fibroplasia phase of wound healing.

- $\quad$ Fibroblasts and keratinocytes can express NK-1R at both protein and transcriptional levels, and this expression is upregulated by SP indicating that these cells and neuropeptide may be involved in the regulation of skin immune responses.

- Cutaneous nociceptive nerve endings are needed in wound healing. The proliferative effect of neuropeptides on fibroblasts may cause disturbances of wound healing, which may be associated with hyperproliferative skin disorders (e.g., keloids) and mesenchymal disorders (e.g., scleroderma).

- The understanding of the neuropeptidergic action on fibroblasts may provide relevant information to a deeper comprehension of the healing process.

- Despite being the most abundant neuropeptide in the skin, only one study was found describing the effects of CGRP in combination with SP and alpha-MSH on cultured human skin fibroblasts and keratinocytes, investigating the IL-8/IL-8R system. The rationale was based on the fact that IL-8 plays an important role in cutaneous inflammation, and that $\mathrm{SP}, \mathrm{CGRP}$, and alpha-MSH also regulate cytokine production. SP and CGRP in concentrations of $10^{-8} \mathrm{M}$ had no effect on the expression of IL-8 and IL-8R in human dermal fibroblasts.
- Further studies are necessary to investigate the action of CGRP on skin fibroblasts and its role in the fibroplasia phase of wound healing.

\section{Introduction}

Neurogenic inflammation is caused by the presence of local neuropeptides, which are special neurotransmitters synthesized mainly in sensory neurons of the dorsal root ganglion [1-3] and released by exocytosis from peptidergic cutaneous C-fibers (unmyelinated afferents or polymodal C-nociceptors), and in smaller amounts by thinly myelinated A-delta fibers [4-6].

Neuropeptides, also called neurotrophins or neurohormones, are released in much smaller amounts than common small-molecule neurotransmitters, such as catecholamines. However, neuropeptides are usually 1000 times more potent than neurotransmitters and act on their target cells by paracrine, juxtacrine or endocrine signaling [7]. While common neurotransmitters act as a pool in a rapid, massive transient manner on target cells, the neuropeptide action is slow and has prolonged effects that may last for days, months or years. Therefore, neuropeptides promote long-lasting changes in the mechanism of cellular metabolism by activating or deactivating specific genes [7].

Calcitonin gene-related peptide (CGRP) is the most abundant neuropeptide in the skin followed by substance $P(S P)$, vasoactive intestinal peptide (VIP), and other neuropeptides in smaller amounts [8]. Usually, nerve endings deep in the dermis contain increased quantities of CGRP, SP, VIP and Neurokinin A (NKA), while those that penetrate the epidermis contain only SP, VIP and NKA $[9,10]$. The cutaneous concentration of neuropeptides changes according to the anatomic location. CGRP is a 37 -amino acid peptide expressed by neurons and endocrine cells in different tissues [11]. Two isoforms of the CGRP peptide have been described: alpha-CGRP, which is formed by the alternative mRNA splicing of the calcitonin gene located on chromosome 11; and beta-CGRP, which is encoded by a different, but closely related gene [11-17]. Alpha-CGRP and beta-CGRP differ from each other by three amino acids in humans and by one amino acid in rats [13,15], and exhibit overlapping biological actions [16].

CGRP acts intensively on sweat glands and perivascular nerves $[9,18]$. The specific receptors, CGRP 1 and CGRP 2 receptors, coupled to the adenylate cyclase system bind to G-proteins [9]. CGRP is the most potent vasodilator known and its vasodilator effect on the skin (which is constant in the arterioles of all studied species) is caused by direct action on the muscle vascular bed. 
Therefore, this effect is independent of endothelial cells and does not involve protein extravasation $[8,19,20]$. Even at concentrations 1000 times that needed to induce vasodilation, CGRP cannot stimulate pruritus or pain in human skin. Also, CGRP has a limited or absent capacity to release histamine from mast cells, although it may induce mast cell degranulation and tumor necrosis factor-alpha (TNF-alpha) release [21]. On the other hand, the trophic effects of CGRP occur at much lower concentrations than that needed to induce vasodilation. CGPR contributes to edema formation induced by interleukins (IL) 1 and 8 (IL-1 and IL-8), increases the expression and synthesis of IL-8 in endothelial cells, is a chemotactic for neutrophils and stimulates the proliferation of keratinocytes in mice [22]. CGRP was shown to accelerate and increase cytokine-dependent IL-6 production in Swiss 3T3 fibroblast culture [23].

$\mathrm{SP}$ is an important member of the tachykinin family. It is an 11-amino acid peptide, which was named "substance $P$ " because it was first obtained as a "powder" [24]. SP and NKA belong to the phylogenetically ancient tachykinin peptide family. Tachykinins are defined structurally by the common C-terminal amino acid sequence Phe-Xaa-Gly-Leu-Met$\mathrm{NH}_{2}$ (Xaa = Phe, Tyr, Val, or Ile) [25]. The mammalian tachykinins are encoded on three different genes, named preprotachykinin (TAC) 1, TAC3 and TAC4 according to the Human Genome Organization (HUGO) [26]. TAC1, the first gene that was cloned from bovine brain, encodes SP. Also, a discrete genomic segment of TAC1 encodes NKA by alternative RNA splicing of the same gene to yield alpha-TAC1 and beta-TAC1 [27]. SP has a similar distribution to CGRP with respect to its targets. SP receptors, neurokinin (NK)-1R, NK-2R and NK-3R, coupled with a G-protein have been described in mast cells, polymorphonuclear leukocytes, monocytes, macrophages, thymus-derived ( $T$ ) lymphocytes (or $\mathrm{T}$ cells), and bone marrow-derived (B) lymphocytes (or $B$ cells) $[9,28]$. SP is one of the most potent vasodilators; it releases nitric oxide from endothelial cells. This effect is 100 times more potent than that of histamine at similar concentrations. SP produces erythema and edema in a dose-dependent manner, but unlike CGRP, it induces plasma extravasation [29]. In addition, SP is chemotactic for T cells, enhances the proliferation and action of $T$ and $B$ cells, induces the expression of IL-1 and IL- 6 by T cells, increases the production of immunoglobulins, the activity of natural killer cells and macrophages, and the production of $\mathrm{LL}-1$ and IL- 6 by T cells, TNF-alpha and prostaglandin E $2 b$ (PGE 2b) mediated by NK-1R. However, unlike CGRP, $\mathrm{SP}$ induces human mast cell degranulation with release of histamine $[9,28]$. SP also induces proliferation of human dermal fibroblasts [30] and human and murine keratinocytes $[31,32]$ and stimulates neovascularization in vivo and proliferation of endothelial and smooth muscle cells $[9,28,33]$. The neuropeptides VIP and CGRP, alone or in combination with SP, stimulate the proliferation of murine [30] and human [34,35] keratinocytes; however, the functional role of VIP and CGRP in skin fibroblasts is not well defined [36]. CGRP has been shown to elicit 3T3 and IMR-90 (Human foetal lung) fibroblasts migration in culture, with a chemotactic and chemokinetic response [37].

The presence of the main neuropeptides CGRP and SP in the skin, as well as of those others occurring in cutaneous nerve endings, is directly controlled by the availability of neural growth factor (NGF). NGF is a peptide synthesized and secreted by keratinocytes, dermal fibroblasts, and Schwann cells $[38,39]$. The inverse also occurs, that is, neurogenic inflammation or the presence of SP and CGRP may induce an increase in the NGF concentration in the skin, indicating the existence of a mutual trophic communication whose importance is still under study, especially regarding tissue repair [40]. SP and CGRP are frequently present in the same nerve fiber. SP release may induce the co-release of CGRP, which in turn may enhance the action of SP, although CGRP may have longlasting effects. Moreover, the release of SP or CGRP may induce an increase in the levels of SP receptors (NK-1R) [32,41,42].

Since 1990's, cutaneous neurogenic inflammation has been studied more extensively [9]. Sympathetically dependent neurogenic inflammation triggers a strong arteriolar vasodilation effect that modulates the amount of inflammatory mediators (such as histamine, arachidonic acid, bradykinin, and prostaglandins, typical of the inflammatory phase that will follow) and the global recruitment of immune-inflammatory cells, which together activate the inflammatory phase of wound healing $[1,2,43,44]$. As a direct consequence, the neurogenic inflammation promotes the release of cytokines and growth factors, inducing extracellular matrix synthesis by fibroblasts in the healing phase. The neurogenic inflammation has a direct modulatory effect on the subsequent phases of the healing process, especially on the proliferative phase [45-47].

Neuropeptides, especially CGRP and SP, have a specific and active participation in the fibrosis process, directly acting in the proliferative phase of wound healing for the production of extracellular matrix $[1,2,4,42]$. Dermal fibroblasts have receptors for these neuropeptides, but their role in these cells is not as well-known as in the neurogenic inflammation phase. The expression of CGRP and adrenomedullin (ADM) receptors in human 
dermal fibroblasts and keratinocytes has been described, but a more profound analysis of the differentiated action of these neuropeptides in these cells is yet to be done [36]. The ability of SP to induce synthesis and proliferation of human dermal fibroblasts and keratinocytes is well known [30,31]. However, the fact that these cells express neuropeptides receptors suggests that they may respond to SP and other neuropeptides [32]. The neuropeptides VIP and CGRP, alone or in combination with SP, stimulate the proliferation of murine [30] and human [34,35] keratinocytes, but the functional role of CGRP in skin fibroblasts is not well defined [36].

Cutaneous nociceptive nerve endings are necessary in wound healing. The proliferative effect of neuropeptides on fibroblasts may cause disturbances of wound healing, which may be associated with hyperproliferative skin disorders (e.g., keloids) and mesenchymal disorders (e.g., scleroderma) [36,48,49]. The understanding of the neuropeptidergic action on fibroblasts may provide relevant information to a deeper comprehension of the healing process. The subject of our study, neuropeptides in experimental in vitro studies, wouldn't allow a proper systematic review due to the intrinsic nature of the articles and of the subject itself. However, a review using a systematization of the literature search strategy could bring significant contribution to the understanding of the action of the major neuropeptides in the proliferative phase of wound healing, after the neurogenic inflammation phase. Besides that, this search strategy systematization allows the review to include all articles exclusively relevant to the subject and, since the search strategy is presented, it also allows the review to be updated at any time. Therefore, the aim of this study was to review the action of the main neuropeptides, CGRP and SP, on cultured human skin fibroblasts.

\section{Methods}

A systematic literature search was conducted on Medline (PubMed) and Web of Science (Thomson Reuters) databases on December 21, 2013. The search strategies were as follows:

(a) PubMed - search 1:

Search ("Calcitonin Gene-Related Peptide"[Mesh] OR "Substance P"[Mesh]) AND "Fibroblasts"[Mesh] AND "Skin"[Mesh] AND “Cells, Cultured"[Mesh]

(b) PubMed - search 2:

Search ("Calcitonin Gene-Related Peptide" OR "Substance P") AND "Fibroblasts" AND "Skin" AND "Cells, Cultured"

(c) Web of Science:
TS $=$ (Fibroblast ${ }^{*}$ AND (Calcitonin-Gene Related Peptide OR Substance P) AND (Skin) AND (Cultured Cell*))

No qualifier or limit was used in the search. Publications found simultaneously in both databases were counted only once. The articles were categorized according to the model used (human or animal), and neuropeptide(s) studied. For the selected articles, we also checked the References section as some important articles couldn't be retrieved by the search criteria. The conclusions of the studies were summarized and review articles were excluded from the study. Articles in which the content was not related to the objectives of the present study were also excluded.

\section{Results}

A total of 74 articles were retrieved using the proposed search strategies of which 14 articles were retrieved from Medline (PubMed search 1), 21 from Medline (PubMed search 2) with a total of 24 different articles from both Pubmed searches (1 and 2), and 50 articles retrieved from Web of Science. However, 13 articles were common to both databases, so that 61 different articles were retrieved. Also, 5 review articles and 46 articles presenting topics not related to the objectives of this study were excluded from the sample. Ten articles were previously selected using the search engines, which studied the action of the main neuropeptides on cultured human skin fibroblasts. For these articles (and for all articles selected thereafter), we also checked the References section, as some relevant articles seemed to have escaped the search criteria. Three new articles were retrieved this way, for a total of 13 articles concerning the action of CGRP and/or SP on cultured human skin fibroblasts, of which 12 were related to SP and 1 was related to both CGRP and SP. A summary of the content of these articles is shown in Table 1 [30,50-61]. A schematic drawing is proposed showing the molecular mechanisms of CGRP and SP in human skin fibroblasts and is shown in Figure 1.

\section{Discussion}

A study has investigated the effects of CGRP, SP and alpha-melanocyte-stimulating hormone (alpha-MSH) on the IL-8/IL-8R system in a cultured human keratinocyte cell line and dermal fibroblasts [50]. The rationale was based on the fact that IL-8 plays an important role in the cutaneous inflammation and SP, CGRP, and alpha-MSH 


\begin{tabular}{|c|c|c|c|}
\hline & Retrived Articles & Neuropeptides & Action on skin fibroblasts \\
\hline 1 & Nilsson et al., 1985 [30] & SP & $\begin{array}{l}\text { SP stimulate DNA synthesis in cultured human skin fibroblasts, and this stimulation is inhibited } \\
\text { by the SP-antagonist spantide. }\end{array}$ \\
\hline 2 & Kiss et al., 1999 [50] & CGRP and SP & $\begin{array}{l}\text { SP and CGRP in concentrations of } 10^{-8} \mathrm{M} \text { had no effect on the expression of Interleukin } 8 \text { (IL-8) } \\
\text { and Interleukin } 8 \text { Receptor (IL-8R) in human dermal fibroblasts. }\end{array}$ \\
\hline 3 & Kähler et al., 1993 [51] & SP & $\begin{array}{l}\text { SP potently stimulated fibroblast growth in the presence of acetylsalicylic acid after growth arrest } \\
\text { by } 48 \text { h serum starvation. } \\
\text { SP stimulated fibroblast growth in a manner typical of competence factors. } \\
\text { Arachidonic acid metabolites were involved in the cell cycle-dependent mitogenic action of SP } \\
\text { on human skin fibroblasts. }\end{array}$ \\
\hline 4 & Kähler et al., 1993 [52] & SP & $\begin{array}{l}\text { SP had a potent chemotactic effect, attracting human dermal fibroblasts in a concentration- } \\
\text { dependent manner. }\end{array}$ \\
\hline 5 & Parenti et al., 1996 [53] & SP & $\begin{array}{l}\text { The addition of SP to cultured human dermal fibroblasts increased the motility of fibroblasts in a } \\
\text { concentration-dependent manner with a } 50 \% \text { increase in migration at a concentration of } 10^{-8} \mathrm{M} \text {. }\end{array}$ \\
\hline 6 & Bae et al., 2002 [54] & SP & Exogenous SP induced autocrine production of SP by human skin fibroblasts. \\
\hline 7 & Liu et al., 2006 [55] & SP & $\begin{array}{l}\text { SP and gamma interferon (IFN-gamma) upregulated the expression of Neurokinin } 1 \text { Receptor } \\
\text { (NK-1R) in human dermal fibroblasts, as well as in HaCaT (a human epidermal keratinocyte cell } \\
\text { line) cells. }\end{array}$ \\
\hline 8 & Kähler et al., 1996 [56] & SP & $\begin{array}{l}\text { The combination of SP with Epidermal Growth Factor (EGF) synergistically stimulated the } \\
\text { proliferation of human dermal fibroblasts and release of PGE } 2 \text {. }\end{array}$ \\
\hline 9 & Hu et al., 2002 [57] & SP & SP increased the proliferation of human fibroblasts in a concentration-dependent manner. \\
\hline 10 & Morbidelli et al., 1993 [58] & SP & $\begin{array}{l}\text { Synthetic selective NK-1R antagonists of human skin fibroblasts induced a significant } \\
\text { displacement to the right of the dose-response curves induced by SP and the selective NK-1R } \\
\text { agonist. } \\
\text { The selective NK-2R antagonist did not modify the proliferative response to the tachykinins used. } \\
\text { The growth-promoting effect of Basic Fibroblast Growth Factor (bFGF) was not changed by any } \\
\text { of the tachykinin antagonists tested. }\end{array}$ \\
\hline 11 & Xie et al., 2011 [59] & SP & $\begin{array}{l}\text { Fibroblastic CD10 expression may down-regulate skin inflammation by degrading SP or } \\
\text { reducing its level in the dermal microenvironment. } \\
\text { Targeted disruption of CD10 by siRNA augmented SP production from Fbs }\end{array}$ \\
\hline 12 & Liu et al., 2007 [60] & SP & $\begin{array}{l}\text { SP induced the production of IFN-gamma, IL-1beta, IL-8 and Monocyte Chemotactic Protein } \\
\text { (MCP)- } 1 \text { in HaCaT cells and human dermal fibroblasts. } \\
\text { Matrine } 5-100 \mu \mathrm{g} / \mathrm{mL} \text { inhibited SP-induced IL-1beta, IL-8 and (MCP)- } 1 \text { production in HaCaT cells } \\
\text { and human dermal fibroblasts, with no effect on IFN-gamma production in both cells. } \\
\text { SP had no effect on IL-6 secretion in HaCaT cells and human dermal fibroblasts. } \\
\text { Fibroblasts did not constitutively secrete Tumor Necrosis Factor-gamma (TNF-gamma). Neither } \\
\text { SP nor matrine induced the secretion of this cytokine. }\end{array}$ \\
\hline 13 & Liu et al., 2008 [61] & SP & $\begin{array}{l}\text { SP induced the production of IFN-gamma, IL-1beta and IL-8 in HaCaT cells and human dermal } \\
\text { fibroblasts. } \\
\text { Cetirizine } 1-100 \text { micromol } \times \text { L(-1) inhibited SP-induced IL-1beta and IL-8 production in HaCaT } \\
\text { cells and human dermal fibroblasts, with no effect on IFN-gamma production in both cells. } \\
\text { SP had no effect on IL-6 secretion in HaCaT cells and human dermal fibroblasts. }\end{array}$ \\
\hline
\end{tabular}

Table 1. Summary of the action of the neuropeptides CGRP and SP on skin fibroblasts.

also regulate cytokine production. The authors reported that alpha-MSH induced a time-dependent expression of IL-8 mRNA in fibroblasts, while SP and CGRP did not act on dermal fibroblasts at a concentration of $10^{-8} \mathrm{ML}^{-1}$. On the otherhand, SP and CGRPupregulated the expression of IL-8 mRNA in keratinocytes, but had no effect on the production of IL-8; alpha-MSH had no effect on either IL-8 or IL-8/L-8R system in these cells [50].

Neuropeptides exert a variety of modulatory effects on inflammatory cellular responses. In order to investigate other activities of neuropeptides in the inflammatory processes, a study has assessed the ability of SP to stimulate chemotaxis in human fibroblasts [51]. Kähler et al. [52] reported that SP was a potent chemoattractant for human fibroblasts in vitro, triggering a concentration-dependent migratory response. When testing the chemoattractant properties of SP fragments, only the C-terminal fragment analog induced migratory responses [52]. It was suggested that chemotactic responsiveness is encoded by the $\mathrm{C}$-terminus of the SP, which is known to be active in NK receptors. The ability of substance $P$ to promote chemotaxis in human fibroblasts, which extends to the fibroplasia phase of wound healing, is another proinflammatory activity of this neuropeptide [52].

Other study has addressed cell migration and the distance human dermal fibroblasts move after the addition of SP to the culture medium [53]. The authors observed an increase in the motility of fibroblasts 


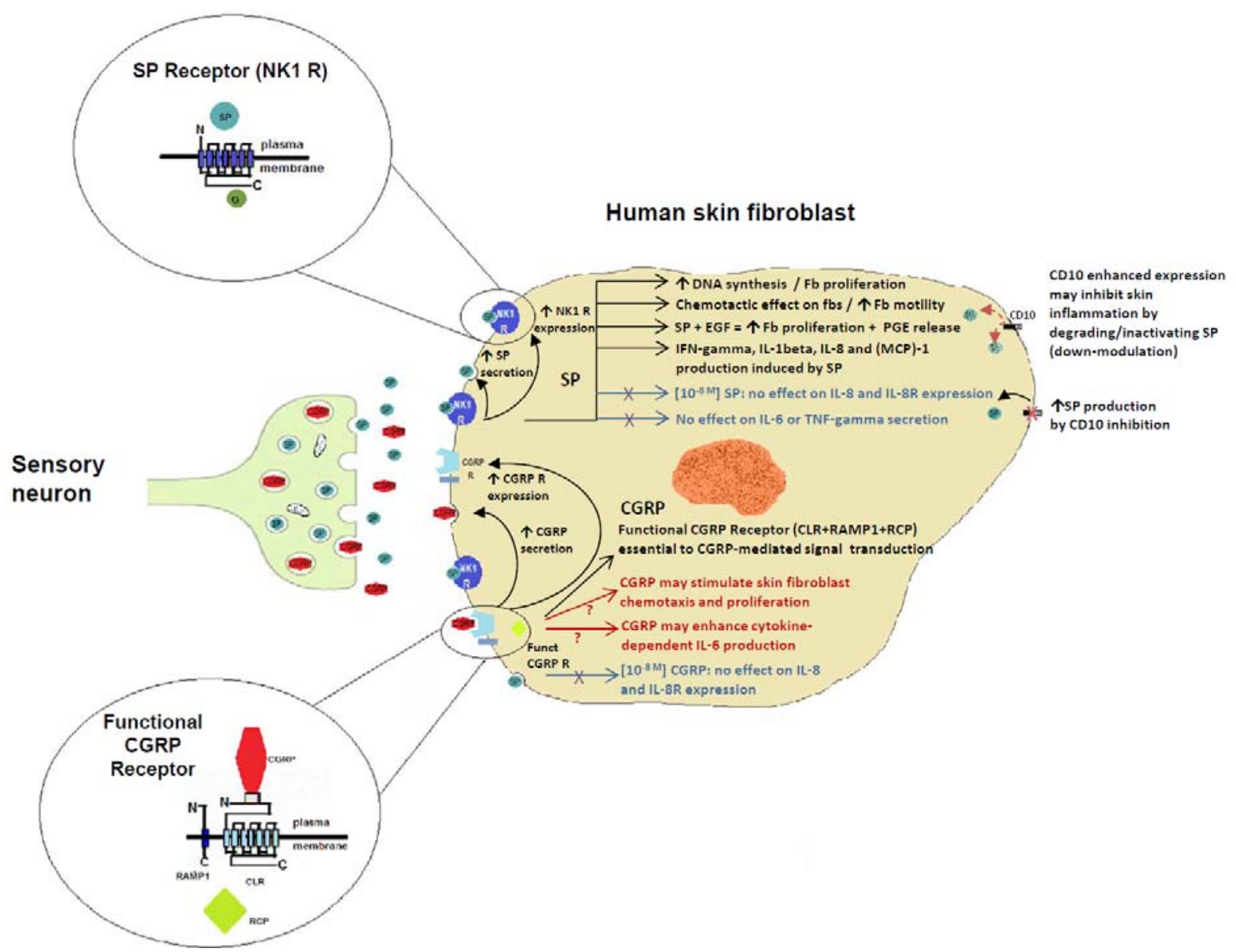

Figure 1. Schematic drawing showing the molecular mechanisms of CGRP and SP in human skin fibroblasts. Fb: Fibroblast; SP: Substance P: CGRP: Calcitonin Gene-Related Peptide; CD10: Cluster of Differentiation 10; EGF : Epidermal Growth Factor ; IL-1 beta: Interleukin 1 beta; IL-6: Interleukin 6; IL-8: Interleukin 8; IL-8R: Interleukin 8 Receptor; IFN-gamma: Gamma Interferon; (MCP)-1: Monocyte Chemotactic Protein 1; PGE: Prostaglandin E; TNF-gamma: Tumor Necrosis Factor-gamma; NK-1 R: Neurokinin 1 Receptor (SP Receptor); CLR : Calcitonin-Like Receptor; RAMP1: Receptor-Activity-Modifying Protein 1; RCP : Receptor Component Protein. Blue arrows: no effect. Red arrows: possible effect.

in a concentration-dependent manner. An SP concentration of $10^{-8} \mathrm{M}$ lead to a $50 \%$ increase in fibroblast migration. SP is a potent effector of fibroblast migration, and NK-1R is responsible for this effect. These observations reinforce the importance of the specific role of NK-1R in mediating the trophic function of SP at the level of skin fibroblasts [53].

Neutral endopeptidase (NEP) is a cell-surface enzyme that degrades SP. NEP mRNA was detected in fibroblasts, keratinocytes and endothelial cells in the skin and wound tissue, which makes this enzyme a possible factor in the attenuation of proinflammatory and mitogenic action of these neuropeptides [62].

A study on the mechanisms that regulate the autocrine induction of SP by cultured human fibroblasts has shown for the first time that SP mRNA, NEP mRNA, and SP may be induced by normal skin fibroblasts in response to exogenous SP [54].
SP can be a possible factor in the pathogenesis of cutaneous allergic inflammation. An investigation of the expression of NK-1R for SP in cultured human dermal fibroblasts and epidermal keratinocytes has reported that fibroblasts and keratinocytes can express NK-1R at both protein and transcriptional levels, and that this expression is upregulated by SP, gamma-interferon (IFN-gamma) and spantide I [55]. This suggests that fibroblasts and keratinocytes may be involved in the regulation of skin immune responses, and that NK-1R may play an important role in the pathogenesis of cutaneous allergic inflammation [55].

SP stimulates the growth and proliferation of human dermal fibroblasts through arachidonic acid metabolites. Other investigations have reported that when cell growth was interrupted due to serum deprivation for more than $48 \mathrm{~h}, \mathrm{SP}$ was not able to stimulate fibroblast proliferation [51]. SP, fibroblast growth factor (FGF) and epidermal 
growth factor (EGF) are mitogenic for fibroblasts [51]. Another investigation has tested the effects of a submaximal concentration of SP $\left(10^{-9} \mathrm{M}\right)$ combined with either FGF or EGF on fibroblast proliferation and release of arachidonic acid metabolites. The authors observed that the combination of SP with EGF synergistically stimulated the proliferation of fibroblasts and release of PGE 2, while the addition of SP to cultures containing FGF had no effect on cell growth. Therefore, the interactions of SP with FGF and EGF differently affect the mitogenic response based on the release of arachidonic acid metabolites [56].

SP also affects the proliferation of skin fibroblasts [52]. A study on the role of SP in the formation of hypertrophic scars has reported that SP increased in vitro proliferation of skin fibroblasts in a dosedependent manner, with maximum rate for an SP concentration of $25 \mathrm{ng} \mathrm{mL}^{-1}$ [58]. Moreover, after $48 \mathrm{~h}$ in culture with SP $\left(25 \mathrm{ng} \mathrm{mL}^{-1}\right)$, fibroblasts expressed more mRNA for transforming growth factor (TGF)-beta 1 than those that were not exposed to the neuropeptide, suggesting that SP may play an important role in the phenotypic changes of fibroblasts during skin healing. A disturbance in the expression of these changes may result in the formation of hypertrophic scars and possibly keloids [57].

The effects of synthetic selective tachykinin receptor antagonists on the growth of cultured human skin fibroblasts have been evaluated [58]. Selective antagonists for the NK-1R and NK-2R were tested against $\mathrm{SP}$, against a selective NK-1R agonist, and against basic fibroblast growth factor (bFGF). All selective NK-1R antagonists tested at the concentration of $10^{-5} \mathrm{M} \mathrm{L}^{-1}$ induced a significant displacement to the right of the dose-response curves induced by SP and by the selective NK-1R agonist. The selective NK-2R antagonist did not change the proliferative response to the tachykinins used. The growth-promoting effect of bFGF was not affected by any of the antagonists tested. These results indicate that the synthetic receptor-selective antagonists may become an important tool to the study of in vitro biological effects of tachykinin on cultured cells [58].

CGRP and ADM couple to the same type of transmembrane receptor, the calcitonin-like receptor (CLR). The selective specificity of CLR for these peptides depends on which members of a family of single-transmembrane-domain proteins, called receptor-activity-modifying proteins (RAMPs), are expressed (i.e., RAMP1, RAMP2 or RAMP3) [63]. The simultaneous expression of CLR and RAMP is essential for the expression of functional receptors. Studies on transfection of different cell types have confirmed this hypothesis [63-65].

COS-7 fibroblasts (African green monkey kidney COS-7 cells) do not express significant levels of endogenous RAMPs [66], but have been commonly used as a transfection model. Transfection of rat CLR, when co-expressed with mRAMP1 in COS-7 cells, results in the expression of a functional CGRP receptor [64].

The rat myogenic cell line L6 is considered a fibroblast cell line and has receptors for CGRP in its endogenous form. The cell line L6 expresses mRNA for RAMP1 and RAMP2; Rat-2 fibroblasts express mRNA only for RAMP2 [67] without receptor for CGRP. Withers et al. [67] reported that Swiss 3T3 fibroblasts have high-affinity receptors for ADM, but no CGRP receptor. On the other hand, Evans et al. [69] detected functional CGRP receptors by cAMP assays in NIH3T3 cells.

Human skin fibroblasts express mRNA for RAMP1, indicating that human skin fibroblasts have lowexpression of (but still express) CGRP receptor [36].

Evans et al. [69], working with NIH3T3 and COS-7 fibroblasts, proposed that a functional CGRP receptor complex requires at least three proteins: the CGRP receptor itself, composed by CLR and RAMP1 (the chaperone protein to route CLR to the cell surface), and a receptor component protein (RCP) to couple the complex CLR + RAMP1 to the cellular signal transduction pathway.

In conclusion, although CGRP is the most abundant neuropeptide in the skin, only one study was found in the literature describing the action of CGRP in combination with SP on cultured human skin fibroblasts. $\mathrm{SP}$ is a neuropeptide that has been shown to exert proliferative and chemoattractant effects on human skin fibroblasts, and to be linked to cutaneous immune reactions. Human skin fibroblasts have low-expression of CGRP receptor. Therefore, further studies are necessary to investigate the action of CGRP on skin fibroblasts and its role in the fibroplasia phase of wound healing.

\section{Acknowledgements}

The authors wish to thank Gabriela Soares Silva Brito, BSc, MSc (Unifesp) and Felipe Contoli Isoldi, MD (Unifesp) for their contribution to this study. 
[1] Holzer P. Neurogenic vasodilatation and plasma leakage in the skin. Gen Pharmacol. 1998; 30:5-11.

[2] Rossi R, Johansson O. Cutaneous innervation and the role of neuronal peptides in cutaneous inflammation: a minireview. Eur J Dermatol. 1998; 8:299-306.

[3] Watson RE, Supowit SC, Zhao H, Katki KA, Dipette DJ. Role of sensory nervous system vasoactive peptides in hypertension. Braz $\mathrm{J}$ Med Biol Res. 2002; 35:1033-45.

[4] Petersen LJ, Church MK, Skov PS. Histamine is released in the wheal but not the flare following challenge of human skin in vivo: a microdialysis study. Clin Exp Allergy. 1997; 27:284-95.

[5] Weidner C, Klede M, Rukwied R, Lischetzki G, Neisius U, Skov PS, Petersen LJ, Schmelz M. Acute effects of substance $P$ and calcitonin generelated peptide in human skin--a microdialysis study. J Invest Dermatol. 2000; 115:1015-20.

[6] Toyoda M, Morohashi M. New aspects in acne inflammation. Dermatology. 2003; 206:17-23.

[7] Steinhoff M, Ständer S, Seeliger S, Ansel JC, Schmelz M, Luger T. Modern aspects of cutaneous neurogenic inflammation. Arch Dermatol. 2003; 139:1479-88.

[8] Esteves Junior I, Ferreira LM, Liebano RE. Peptídeo relacionado ao gene da calcitonina por iontoforese na viabilidade de retalho cutâneo randômico em ratos [Calcitonin gene-related peptide by iontophoresis on the viability of the randon skin flaps in rats]. Acta Cir Bras. 2004; 19:626-9.

[9] Lotti T, Hautmann G, Panconesi E. Neuropeptides in skin. J Am Acad Dermatol. 1995; 33:482-96.

[10] Hagner S, Haberberger RV, Overkamp D, Hoffmann R, Voigt KH, McGregor GP. Expression and distribution of calcitonin receptor-like receptor in human hairy skin. Peptides. 2002; 23:109-16.

[11] Amara SG, Jonas V, Rosenfeld MG, Ong ES, Evans RM. Alternative RNA processing in calcitonin gene expression generates mRNAs encoding different polypeptide products. Nature. 1982; 298:240-4.

[12] Rosenfeld MG, Mermod JJ, Amara SG, Swanson LW, Sawchenko PE, Rivier J, Vale WW, Evans RM . Production of a novel neuropeptide encoded by the calcitonin gene via tissue-specific RNA processing. Nature. 1983; 304:129-35.

[13] Amara SG, Evans RM, Rosenfeld MG. Calcitonin/ calcitonin gene-related peptide transcription unit: tissue-specific expression involves selective use of alternative polyadenylation sites. Mol Cell Biol. 1984; 4:2151-60.

[14] Goodman EC, Iversen LL. Calcitonin gene-related peptide: novel neuropeptide. Life Sci. 1986; 38:2169-2178.

[15] Breimer LH, Maclntyre I, Zaidi M. Peptides from the calcitonin genes: molecular genetics, structure and function. Biochem J. 1988; 255:377-90.

[16] Brain SD, Grant AD. Vascular actions of calcitonin gene-related peptide and adrenomedullin. Physiol Rev. 2004; 84:903-34.

[17] Peters EM, Ericson ME, Hosoi J, Seiffert K, Hordinsky MK, Ansel JC, Paus R, Scholzen TE. Neuropeptide control mechanisms in cutaneous biology: physiological and clinical significance. J Invest Dermatol. 2006; 126:1937-47.

[18] Kakizoe E, Kobayashi Y, Gonda T, Shimoura K, Hattori K, Okunishi $H$. Synergistic interactions between neuropeptide and histamine on the capillary permeability in rat skin: evaluation by reflectance spectrophotometry. Microvasc Res. 1997; 54:27-34.

[19] Slominski A, Wortsman J. Neuroendocrinology of the skin. Endocr Rev. 2000; 21:457-87.

[20] Sleijffers A, Herreilers M, van Loveren H, Garssen J. Ultraviolet $B$ radiation induces upregulation of calcitonin gene-related peptide levels in human Finn chamber skin samples. J Photochem Photobiol B. 2003; 69:149-52.

[21] Seiffert K, Granstein RD. Neuropeptides and neuroendocrine hormones in ultraviolet radiationinduced immunosuppression. Methods. 2002; 28:97-103.

[22] Seike $M$, Ikeda $M$, Morimoto A, Matsumoto $M$, Kodama $\mathrm{H}$. Increased synthesis of calcitonin generelated peptide stimulates keratinocyte proliferation in murine UVB-irradiated skin. J Dermatol Sci. 2002; 28:135-43.

[23] Sakuta H, Inaba K, Muramatsu S. Calcitonin generelated peptide enhances cytokine-induced IL-6 production by fibroblasts. Cell Immunol. 1995; 165(1):20-5.

[24] V Euler US, Gaddum JH. An unidentified depressor substance in certain tissue extracts. J Physiol. 1931;72(1):74-87.

[25] Johansson A, Holmgren S, Conlon JM. The primary structures and myotropic activities of two tachykinins isolated from the African clawed frog, Xenopus laevis. Regul Pept. 2002; 108:113-21.

[26] Patacchini R, Lecci A, Holzer P, Maggi CA. Newly discovered tachykinins raise new questions 
about their peripheral roles and the tachykinin nomenclature. Trends Pharmacol Sci. 2004; 25:13.

[27] Nawa H, Kotani H, Nakanishi S. Tissue-specific generation of two preprotachykinin mRNAs from one gene by alternative RNA splicing. Nature. 1984; 312:729-734.

[28] Schmelz M, Petersen LJ. Neurogenic inflammation in human and rodent skin. News Physiol Sci. 2001; 16:33-7.

[29] Cappugi P, Tsampau D, Lotti T. Substance $P$ provokes cutaneous erythema and edema through a histamine-independent pathway. Int J Dermatol. 1992; 31:206-9.

[30] Nilsson J, von Euler AM, Dalsgaard CJ. Stimulation of connective tissue cell growth by substance $P$ and substance K. Nature. 1985; 315:61-3.

[31] Tanaka T, Danno K, Ikai K, Imamura S. Effects of substance $P$ and substance $K$ on the growth of cultured keratinocytes. J Invest Dermatol. 1988; 90:399-401.

[32] Scholzen T, Armstrong CA, Bunnett NW, Luger TA, Olerud JE, Ansel JC. Neuropeptides in the skin: interactions between the neuroendocrine and the skin immune systems. Exp Dermatol. 1998; 7:8196.

[33] Okabe T, Hide M, Koro O, Yamamoto S. Substance $P$ induces tumor necrosis factor-alpha release from human skin via mitogen-activated protein kinase. Eur J Pharmacol. 2000; 398:309-15.

[34] Takahashi K, Nakanishi S, Imamura S. Direct effects of cutaneous neuropeptides on adenylyl cyclase activity and proliferation in a keratinocyte cell line: stimulation of cyclic AMP formation by CGRP and VIP/PHM, and inhibition by NPY through $G$ protein-coupled receptors. J Invest Dermatol. 1993; 101:646-51.

[35] Kakurai M, Fujita N, Kiyosawa T, Inoue T, Ishibashi S, Furukawa Y, Demitsu T, Nakagawa H. Vasoactive intestinal peptide and cytokines enhance stem cell factor production from epidermal keratinocytes DJM-1. J Invest Dermatol. 2002; 119:1183-8.

[36] Albertin G, Carraro G, Parnigotto PP, Conconi MT, Ziolkowska A, Malendowicz LK, Nussdorfer GG. Human skin keratinocytes and fibroblasts express adrenomedullin and its receptors, and adrenomedullin enhances their growth in vitro by stimulating proliferation and inhibiting apoptosis. Int J Mol Med. 2003; 11:635-9.

[37] Yule KA, White SR. Migration of 3 T3 and lung fibroblasts in response to calcitonin gene-related peptide and bombesin. Exp Lung Res. 1999; 25(3):261-73.
[38] Donnerer J, Schuligoi R, Stein C. Increased content and transport of substance $P$ and calcitonin gene-related peptide in sensory nerves innervating inflamed tissue: evidence for a regulatory function of nerve growth factor in vivo. Neuroscience. 1992; 49:693-8.

[39] Amann R, Sirinathsinghji DJ, Donnerer J, Liebmann I, Schuligoi R. Stimulation by nerve growth factor of neuropeptide synthesis in the adult rat in vivo: bilateral response to unilateral intraplantar injections. Neurosci Lett. 1996; 203:171-4.

[40] Amann R, Egger T, Schuligoi R. The tachykinin $\mathrm{NK}(1)$ receptor antagonist SR140333 prevents the increase of nerve growth factor in rat paw skin induced by substance $\mathrm{P}$ or neurogenic inflammation. Neuroscience. 2000; 100:611-5.

[41] Wallengren J. Vasoactive peptides in the skin. J Investig Dermatol Symp Proc. 1997; 2:49-55.

[42] Wu H, Guan C, Qin X, Xiang Y, Qi M, Luo Z, Zhang $C$. Upregulation of substance $P$ receptor expression by calcitonin gene-related peptide, a possible cooperative action of two neuropeptides involved in airway inflammation. Pulm Pharmacol Ther. 2007; 20:513-24.

[43] Baluk P. Neurogenic inflammation in skin and airways. J Investig Dermatol Symp Proc. 1997; 2:76-81.

[44] Sauerstein K, Klede M, Hilliges M, Schmelz M. Electrically evoked neuropeptide release and neurogenic inflammation differ between rat and human skin. J Physiol. 2000; 529:803-10.

[45] Akaishi S, Ogawa R, Hyakusoku H. Keloid and hypertrophic scar: neurogenic inflammation hypotheses. Med Hypotheses. 2008; 71:32-8.

[46] Hochman B, Nahas FX, Sobral CS, Arias V, Locali RF, Juliano Y, Ferreira LM. Nerve fibres: a possible role in keloid pathogenesis. Br J Dermatol. 2008; 158:651-2.

[47] Ferreira LM, Gragnani A, Furtado F, Hochman B. Control of the skin scarring response. An Acad Bras Cienc. 2009; 81:623-9.

[48] Stelnicki EJ, Doolabh V, Lee S, Levis C, Baumann FG, Longaker MT, Mackinnon S. Nerve dependency in scarless fetal wound healing. Plast Reconstr Surg. 2000; 105:140-7.

[49] Tucci-Viegas VM, Hochman B, Franca JP, Ferreira LM. Keloid explant culture: a model for keloid fibroblasts isolation and cultivation based on the biological differences of its specific regions. Int Wound J. 2010; 7:339-48.

[50] Kiss M, Kemény L, Gyulai R, Michel G, Husz S, Kovács R, Dobozy A, Ruzicka T. Effects of the neuropeptides substance $P$, calcitonin gene- 
related peptide and alpha-melanocyte-stimulating hormone on the IL-8/IL-8 receptor system in a cultured human keratinocyte cell line and dermal fibroblasts. Inflammation. 1999; 23:557-67.

[51] Kähler CM, Herold M, Wiedermann CJ. Substance $P$ : a competence factor for human fibroblast proliferation that induces the release of growth-regulatory arachidonic acid metabolites. J Cell Physiol. 1993; 156:579-87.

[52] Kähler CM, Sitte BA, Reinisch N, Wiedermann CJ. Stimulation of the chemotactic migration of human fibroblasts by substance P. Eur J Pharmacol. 1993; 249:281-286.

[53] Parenti A, Amerini S, Ledda F, Maggi CA, Ziche $M$. The tachykinin NK1 receptor mediates the migration-promoting effect of substance $P$ on human skin fibroblasts in culture. Naunyn Schmiedebergs Arch Pharmacol. 1996; 353:47581.

[54] Bae SJ, Matsunaga Y, Takenaka M, Tanaka Y, Hamazaki Y, Shimizu K, Katayama I. Substance $P$ induced preprotachykinin-a mRNA, neutral endopeptidase mRNA and substance $P$ in cultured normal fibroblasts. Int Arch Allergy Immunol. 2002; 127:316-21.

[55] Liu JY, Hu JH, Zhu QG, Li FQ, Sun HJ. Substance $P$ receptor expression in human skin keratinocytes and fibroblasts. $\mathrm{Br} \mathrm{J}$ Dermatol. 2006; 155:657-62.

[56] Kähler CM, Herold M, Reinisch N, Wiedermann CJ. Interaction of substance $P$ with epidermal growth factor and fibroblast growth factor in cyclooxygenase-dependent proliferation of human skin fibroblasts. J Cell Physiol. 1996; 166:601-8.

[57] Hu D, Chen B, Zhu X, Tao K, Tang C, Wang J. Substance $P$ up-regulates the TGF-beta 1 mRNA expression of human dermal fibroblasts in vitro. Zhonghua Zheng Xing Wai Ke Za Zhi. 2002; 18:234-6

[58] Morbidelli L, Maggi CA, Ziche M. Effect of selective tachykinin receptor antagonists on the growth of human skin fibroblasts. Neuropeptides. 1993; 24:335-41.

[59] Xie L, Takahara M, Nakahara T, Oba J, Uchi H, Takeuchi S, Moroi Y, Furue M. CD10-bearing fibroblasts may inhibit skin inflammation by down-modulating substance P. Arch Dermatol Res. 2011;303(1):49-55
[60] Liu JY, Hu JH, Zhu QG, Li FQ, Wang J, Sun HJ. Effect of matrine on the expression of substance $P$ receptor and inflammatory cytokines production in human skin keratinocytes and fibroblasts. Int Immunopharmacol. 2007; 7(6):816-23.

[61] Liu JY, Zhao YZ, Peng C, Li FQ, Zhu QG, Hu JH. Effect of cetirizine hydrochloride on the expression of substance $\mathrm{P}$ receptor and cytokines production in human epidermal keratinocytes and dermal fibroblasts. Yao Xue Xue Bao. 2008;43(4):383-7.

[62] Olerud JE, Usui ML, Seckin D, Chiu DS, Haycox CL, Song IS, Ansel JC, Bunnett NW. Neutral endopeptidase expression and distribution in human skin and wounds. J Invest Dermatol. 1999; 112:873-81.

[63] McLatchie LM, Fraser NJ, Main MJ, Wise A, Brown J, Thompson N, Solari R, Lee MG, Foord SM. RAMPs regulate the transport and ligand specificity of the calcitonin-receptor-like receptor. Nature. 1998; 393:333-9.

[64] Husmann K, Sexton PM, Fischer JA, Born W. Mouse receptor-activity-modifying proteins $1,-2$ and -3 : amino acid sequence, expression and function. Mol Cell Endocrinol. 2000; 162:35-43.

[65] Chakravarty P, Suthar TP, Coppock HA, Nicholl CG, Bloom SR, Legon S, Smith DM. CGRP and adrenomedullin binding correlates with transcript levels for calcitonin receptor-like receptor (CRLR) and receptor activity modifying proteins (RAMPs) in rat tissues. Br J Pharmacol. 2000; 130:189-95

[66] Bailey RJ, Hay DL. Pharmacology of the human CGRP1 receptor in Cos 7 cells. Peptides. 2006; 27:1367-75.

[67] Choksi T, Hay DL, Legon S, Poyner DR, Hagner $\mathrm{S}$, Bloom SR, Smith DM. Comparison of the expression of calcitonin receptor-like receptor (CRLR) and receptor activity modifying proteins (RAMPs) with CGRP and adrenomedullin binding in cell lines. Br J Pharmacol. 2002; 136:784-92.

[68] Withers DJ, Coppock HA, Seufferlein T, Smith DM, Bloom SR, Rozengurt E. Adrenomedullin stimulates DNA synthesis and cell proliferation via elevation of CAMP in Swiss 3T3 cells. FEBS Lett. 1996; 378:83-7.

[69] Evans BN, Rosenblatt MI, Mnayer LO, Oliver KR, Dickerson IM. CGRP-RCP, a novel protein required for signal transduction at calcitonin gene-related peptide and adrenomedullin receptors. J Biol Chem. 2000; 275(40):31438-43. 